\title{
Chain extension and branching of poly(L-lactic acid) produced by reaction with a DGEBA-based epoxy resin
}

\author{
Z. F. Zhou, G. Q. Huang, W. B. Xu*, F. M. Ren \\ Department of Polymer Science and Engineering, Hefei University of Technology, Hefei, Anhui 230009, China
}

Received 12 August 2007; accepted in revised form 20 September 2007

\begin{abstract}
Dicarboxylated poly(L-lactic acid) (PLLA) was synthesized by reacting succinic anhydride with L-lactic acid prepolymer prepared by melt polycondensation. PLLA and epoxy resin based on diglycidyl ether of bisphenol A (DGEBA) copolymers were prepared by chain extension of dicarboxylated PLLA with DGEBA. Infrared spectra confirmed the formation of dicarboxylated PLLA and PLLA/DGEBA copolymer. Influences of reaction temperature, reaction time, and the amount of DGEBA on the molecular weight and gel content of PLLA/DGEBA copolymer were studied. The viscosity average molecular weight of PLLA/DGEBA copolymer reached 87900 when reaction temperature, reaction time, and mol ratio of dicarboxylated PLLA to DGEBA is $150^{\circ} \mathrm{C}, 30 \mathrm{~min}$, and 1:1 respectively, while gel content of PLLA/DGEBA copolymer is almost zero.
\end{abstract}

Keywords: biodegradable polymers, poly(L-lactic acid), epoxy resin, copolymers

\section{Introduction}

Poly(L-lactic acid) (PLLA) is a completely biodegradable and well biocompatible aliphatic polyester [1]. PLLA has many potential applications in packaging and consumer goods due to its excellent mechanical properties, transparency, compatibility, and biosafety $[2,3]$.

There are generally two ways to synthesize PLLA, ring-opening polymerization and direct polycondensation [4]. Ring-opening polymerization requires highly purified L-lactid, which makes PLLA rather expensive, hardly competitive with current polymers [5, 6]. Direct melt polycondensation can simplify the synthetic process and reduces the cost of PLLA. However, it is difficult to prepare PLLA with high molecular weight by direct polycondensation because of the complicated equilibrium among lactic acid, $\mathrm{H}_{2} \mathrm{O}$, L-lactid and PLA during the process [7]. The unfavorable reaction equilibrium constant makes the PLLA molecular weight in order of only $\sim 10^{4} \mathrm{~g} / \mathrm{mol}$. Such low molecular weight PLLA is too brittle to be used as a useful material [8]. PLLA should have at least $\sim 10^{5} \mathrm{~g} / \mathrm{mol}$ order of molecular weight to exhibit an acceptable level of mechanical properties [9]. Increasing of the molecular weight of PLLA is imperatively demanded [8].

The low molecular weight PLLA synthesized by direct melt polycondensation has reactive functional groups such as hydroxyl and carboxyl group, and its molecular weight can be improved through chain extension. Woo et al. [10] used hexamethylene diisocyanate (HDI) as chain extender, and the average molecular weight of PLLA was improved to 76000 . Kylma and Seppala [11] prepared hydroxyl-terminated PLLA oligomer, used HDI as chain extender, and got the poly(ester-urethane) elastomer. Zhou et al. [12] first synthesized telechelic poly(ethylene glycol) (PEG) by reacting PEG with isophorone diisocyanate (IPDI), then

*Corresponding author, e-mail: xwb105105@sina.com

(c) BME-PT and GTE 
prepared PLLA/PEG multiblock copolymers by coupling reactions between PEG telechelic oligomer and L-lactic acid prepolymer. The elongation at break of the resulting copolymer can reach $320 \%$. Cohn et al. [13] synthesized a series of poly(ethylene oxide)/poly(L-lactic acid) multiblock poly(ether-ester-urethane)s using HDI as extender. It is obvious that isocyanate is widely used as chain extender. However, it has high volatility and toxicity. This will do harm to experiments and pollutes the environment.

Huh et al. [14] first synthesized PLLA with carboxylated end-groups by direct polycondensation, then prepared PEG/PLLA copolymer by polycondensation reaction between PEG and PLLA. This is a new method to increase the molecular weight of PLLA. However, the method requires the presence of solvent and further purification of the products. In addition, the chain extension requires long reaction time.

In this paper a DGEBA-based epoxy resin, which has nearly no volatility and toxicity was used to extend the carboxyl-terminated PLLA in short reaction time in melt, and resulting in high molecular weight products. This method avoids the shortages of the previous techniques and has rarely been reported in published articles so far.

\section{Experimental}

\subsection{Materials}

L-lactic acid (85 wt\%, L-lactic acid content: 9899\%) was purchased from Purac Biochem Co.

(Holland). The impurity was removed before use by distillation under reduced pressure at $130^{\circ} \mathrm{C}$ for about $2 \mathrm{~h}$.

Stannous octoate $\left(\mathrm{Sn}(\mathrm{Otc})_{2}\right)$, succinic anhydride, p-toluenesulfonic acid monohydrate (TSA), tetrahydrofuran (THF), acetone, tetrabutylammonium bromide (TBAB), and DGEBA-based epoxy resin (226.2 $\mathrm{g} / \mathrm{mol}$ epoxy groups) were obtained from Shanghai Chemicals, and used as received without further treatment.

\subsection{Preparation of dicarboxylated PLLA}

The melt polycondensation of L-lactic acid was carried out in a rotavapor equipped with a thermostated oil bath. The rotation speed was $120 \mathrm{rpm}$. $200 \mathrm{~g}$ purified L-lactic acid, $0.5 \mathrm{wt} \%$ catalyst $\mathrm{Sn}(\mathrm{Otc})_{2}$ and $0.5 \mathrm{wt} \%$ co-catalyst TSA were put into a $500 \mathrm{ml}$ round-bottom flask. The reaction temperature was gradually raised from 150 to $180^{\circ} \mathrm{C}$ and the pressure was lowered from 5000 to $100 \mathrm{~Pa}$. After a total reaction time of about $12 \mathrm{~h}$ the L-lactic acid prepolymer was obtained. Then, the desired amount of succinic anhydride was added to the flask. The reaction of succinic anhydride with L-lactic acid prepolymer was carried out at $180^{\circ} \mathrm{C}$ and $100 \mathrm{~Pa}$ for $1 \mathrm{~h}$. The molten polymer was poured into a stainless steel pan and placed in a desiccator to cool down. The dicarboxylated PLLA, with a viscosity average molecular weight of 10070 , was obtained.

\subsection{Chain extension reaction}

The chain extension reaction of dicarboxylated PLLA with DGEBA was also carried out in rotava-

Table 1. Experimental conditions for chain extension reaction ${ }^{\mathrm{a}}$

\begin{tabular}{|c|c|c|c|c|c|c|}
\hline Series & Run number & $\begin{array}{c}\text { PLLA } \\
{[\mathrm{g}]}\end{array}$ & $\begin{array}{c}\text { DGEBA } \\
{[\mathrm{g}]}\end{array}$ & $\begin{array}{c}\text { TABA } \\
{[\mathrm{g}]}\end{array}$ & $\begin{array}{l}\text { Reaction time } \\
{[\mathrm{min}]}\end{array}$ & $\begin{array}{c}\text { Reaction temperature } \\
{\left[{ }^{\circ} \mathbf{C}\right]}\end{array}$ \\
\hline \multirow{5}{*}{ A } & A1 & 73.7 & 12.0 & 0.86 & 30 & 140 \\
\hline & A2 & 73.7 & 12.0 & 0.86 & 30 & 150 \\
\hline & A3 & 73.7 & 12.0 & 0.86 & 30 & 160 \\
\hline & A4 & 73.7 & 12.0 & 0.86 & 30 & 170 \\
\hline & A5 & 73.7 & 12.0 & 0.86 & 30 & 180 \\
\hline \multirow{4}{*}{ B } & B1 & 61.4 & 10.0 & 0.71 & 10 & 150 \\
\hline & B2 & 61.4 & 10.0 & 0.71 & 20 & 150 \\
\hline & B3 & 61.4 & 10.0 & 0.71 & 30 & 150 \\
\hline & B4 & 61.4 & 10.0 & 0.71 & 40 & 150 \\
\hline \multirow{4}{*}{$\mathrm{C}$} & $\mathrm{C} 1$ & 70.0 & 5.7 & 0.70 & 30 & 150 \\
\hline & $\mathrm{C} 2$ & 70.0 & 7.6 & 0.70 & 30 & 150 \\
\hline & $\mathrm{C} 3$ & 70.0 & 11.4 & 0.70 & 30 & 150 \\
\hline & $\mathrm{C} 4$ & 70.0 & 17.1 & 0.70 & 30 & 150 \\
\hline
\end{tabular}

apressure, $100 \mathrm{~Pa}$ in series $\mathrm{A}, \mathrm{B}$ and $\mathrm{C}$ 
por. The rotation speed was $150 \mathrm{rpm}$. The predetermined amount of dicarboxylated PLLA, DGEBA and $\mathrm{TBAB}$ catalyst were put into a $500 \mathrm{ml}$ roundbottom flask. The reaction was performed at $100 \mathrm{~Pa}$ and desired temperature and time. Chain extension reaction conditions for all the series of experiments are summarized in Table 1.

\subsection{Analysis and characterization}

The amount of carboxyl group in L-lactic acid prepolymer and dicarboxylated PLLA was determined as following steps. $0.20 \mathrm{~g}$ sample was dissolved in $40 \mathrm{ml} \mathrm{THF}$, and then titrated by $0.1 \mathrm{~mol} / \mathrm{l} \mathrm{NaOH}$ ethanol solution using phenolphthalein as indicator. The amount of carboxyl group (AC) is given by Equation (1):

$$
A C[\mathrm{~mol} / \mathrm{g}]=\frac{\left(V_{1}-V_{0}\right) \cdot 10^{-3} \cdot C}{m}
$$

where $V_{0}$ the amount of $\mathrm{NaOH}$ consumed by using THF as reference [ml], $V_{1}$ is the amount of $\mathrm{NaOH}$ consumed by sample [ml], $C$ is the mol concentration of titration solution [mol/l], $m$ is the weight of sample $[\mathrm{g}]$.

The gel content (GC) of PLLA/DGEBA copolymer was determined by extraction. The rough sample was extracted by THF using Soxhlet extractor. The crosslinked copolymer, which remained in extractor, was dried to constant weight in vacuum oven at $80^{\circ} \mathrm{C}$. The uncrosslinked copolymer was extracted from the rough sample by THF. The GC is given by Equation (2):

$$
G C[\%]=\frac{m_{2}}{m_{1}} \cdot 100
$$

where $m_{1}$ is the weight of rough sample [g] and $m_{2}$ is the weight of crosslinked copolymer $[\mathrm{g}]$.
The viscosity average molecular weight of dicarboxylated PLLA and uncrosslinked PLLA/DGEBA copolymer was measured by the intrinsic viscosity method. The viscosity was determined in THF at $30^{\circ} \mathrm{C}$ by using a viscometer. The intrinsic viscosity was calculated from the equation of Rongshi Cheng [15], given by Equation (3). The Mark-Houwink equation is given by Equation (4) [16]:

$$
[\eta]=\frac{\sqrt{2\left(\eta_{s p}-\ln \eta_{r}\right)}}{c}
$$

$$
[\eta]=1.29 \cdot 10^{-4} \bar{M}_{V}^{0.82}
$$

Infrared spectroscopic information of polymers was obtained using Spectrum 100 Fourier Transform Infrared spectrophotometer (PE Corp. USA).

\section{Reaction mechanism}

The chemical structures of DGEBA and dicarboxylated PLLA are shown in Figure 1. Synthesis of PLLA/DGEBA copolymers involves following steps: (1) Melt polycondensation of L-lactic acid to prepare L-lactic acid prepolymer. (2) L-lactic acid prepolymer reacting with succinic anhydride to prepare dicarboxylated PLLA. (3) Dicarboxylated PLLA reacting with DGEBA to prepare PLLA/ DGEBA copolymers. The epoxy-acid reaction is complex in the presence of TABA [17]. The reaction mechanism of dicarboxylated PLLA reacting with DGEBA may be described as Figure 2. The linear molecule is obtained as reaction I, while the ester formed by the epoxy-acid reaction can react with the $\mathrm{OH}$ groups through a transesterification reaction as reaction II. The reaction II leads to chain branching and gel formation.

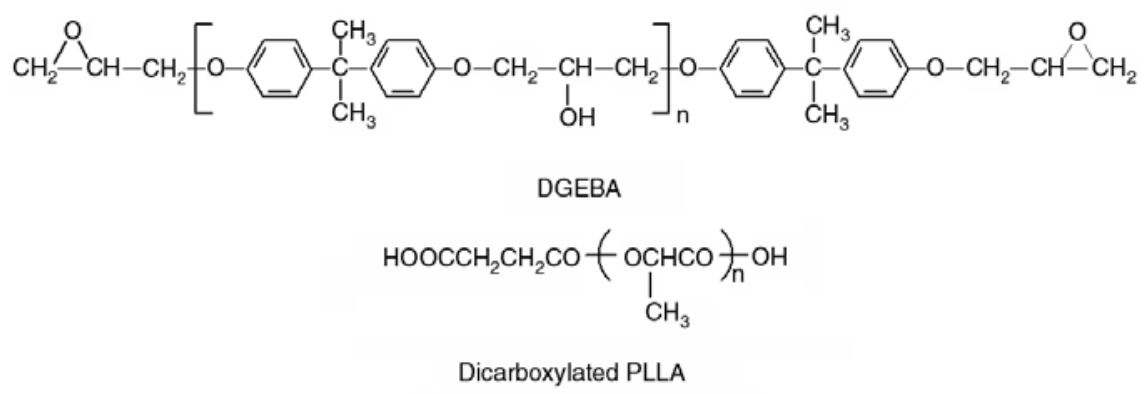

Figure 1. Chemical structures of DGEBA and dicarboxylated PLLA 


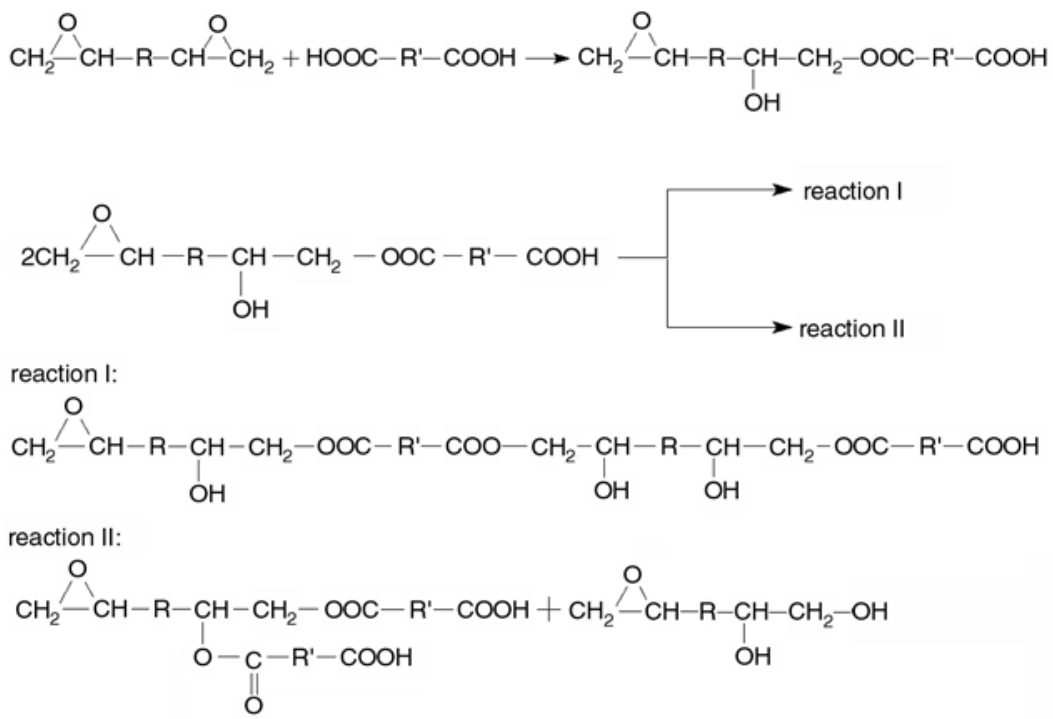

Figure 2. The reaction mechanism of dicarboxylated PLLA reacting with DGEBA

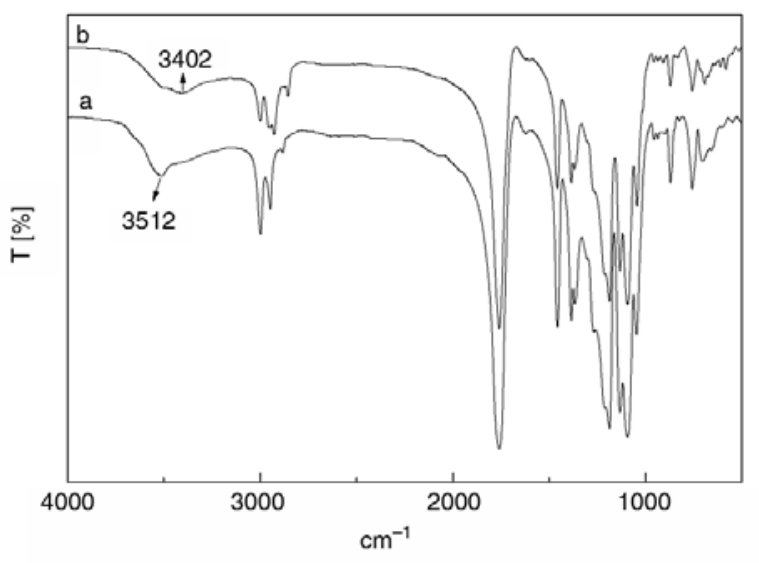

Figure 3. IR spectra of L-lactic acid prepolymer and dicarboxylated PLLA. (a) L-lactic acid prepolymer; (b) dicarboxylated PLLA

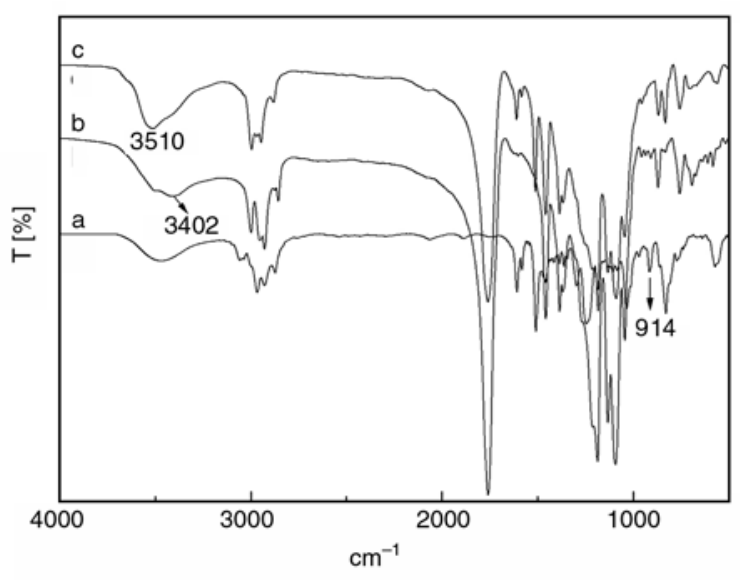

Figure 4. IR spectra of dicarboxylated PLLA, DGEBA and PLLA/DGEBA copolymer. (a) DGEBA; (b) dicarboxylated PLLA; (c) PLLA/DGEBA copolymer

\section{Results and discussion}

\subsection{Evidence of reaction}

Figure 3 shows the infrared spectra of L-lactic acid prepolymer and dicarboxylated PLLA. The absorbance at $3512 \mathrm{~cm}^{-1}$ in Figure 3 (a) indicates the terminal $-\mathrm{OH}$ of L-lactic acid prepolymer. The absence of $3512 \mathrm{~cm}^{-1}$ in Figure 3 (b) indicates that the terminal $-\mathrm{OH}$ of L-lactic acid prepolymer was transformed to terminal $-\mathrm{COOH}$ of dicarboxylated PLLA $\left(3402 \mathrm{~cm}^{-1}\right)$. The amount of carboxyl group of L-lactic acid prepolymer and dicarboxylated PLLA is $3.7 \cdot 10^{-4}$ and $7.2 \cdot 10^{-4} \mathrm{~mol} / \mathrm{g}$, respectively. The infrared spectra of dicarboxylated PLLA, DGEBA and PLLA/DGEBA copolymer are shown in Figure 4. The absorbance at $914 \mathrm{~cm}^{-1}$ in Figure 4 (a) and $3402 \mathrm{~cm}^{-1}$ in Figure 4 (b) indicates the terminal epoxy group of DGEBA and carboxyl group of dicarboxylated PLLA, respectively. The appearance of new absorbance at $3510 \mathrm{~cm}^{-1}$ and absence of $914 \mathrm{~cm}^{-1}, 3402 \mathrm{~cm}^{-1}$ in Figure 4 (c) indicates that the epoxy group of DGEBA and carboxyl group of dicarboxylated PLLA was transformed to hydroxyl group of PLLA/DGEBA copolymer.

\subsection{Effect of reaction temperature}

Figure 5 shows the effect of reaction temperature on the $\overline{M_{V}}$ of uncrosslinked PLLA/DGEBA copolymer and gel content of PLLA/DGEBA copolymer. The experimental conditions are shown in series $A$ of Table 1. The mol ratio of dicarboxylated PLLA 


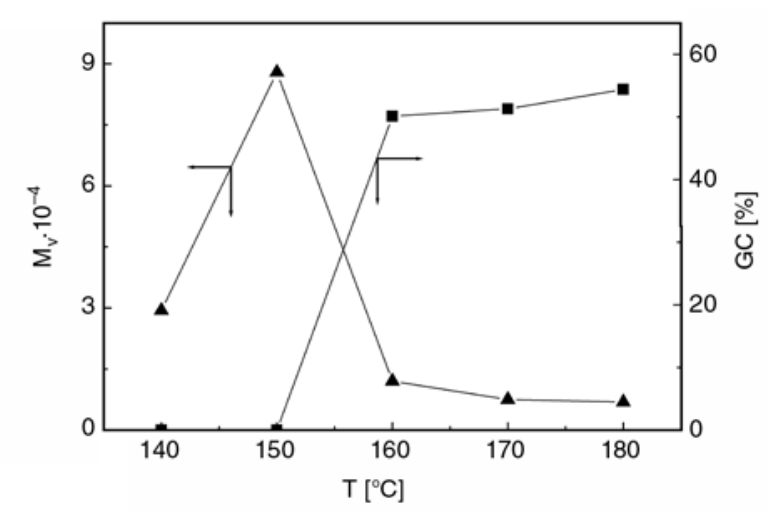

Figure 5. Effect of reaction temperature on chain extension reaction

to DGEBA is $1: 1$. Figure 5 reveals that the $\bar{M}_{V}$ of uncrosslinked PLLA/DGEBA copolymer is the highest when the reaction temperature is $150^{\circ} \mathrm{C}$. The gel content of PLLA/DGEBA copolymer is almost zero when temperature is lower than $150^{\circ} \mathrm{C}$, it increases rapidly with increasing reaction temperature during $150-160^{\circ} \mathrm{C}$, and after that it changes indistinctively. The transesterification reaction (reaction II) is more difficult than that of linear reaction (reaction I) in Figure 2, as a result, no gel content was observed at low temperature. The reaction of transesterification reaction increased considerably when reaction temperature increased, so the gel content of PLLA/DGEBA copolymer increased with increasing reaction temperature.

\subsection{Effect of reaction time}

Figure 6 shows the effect of reaction time on the $\bar{M}_{V}$ of uncrosslinked PLLA/DGEBA copolymer and gel content of PLLA/DGEBA copolymer. The experimental conditions are shown in series $B$ of Table 1. The mol ratio of dicarboxylated PLLA to

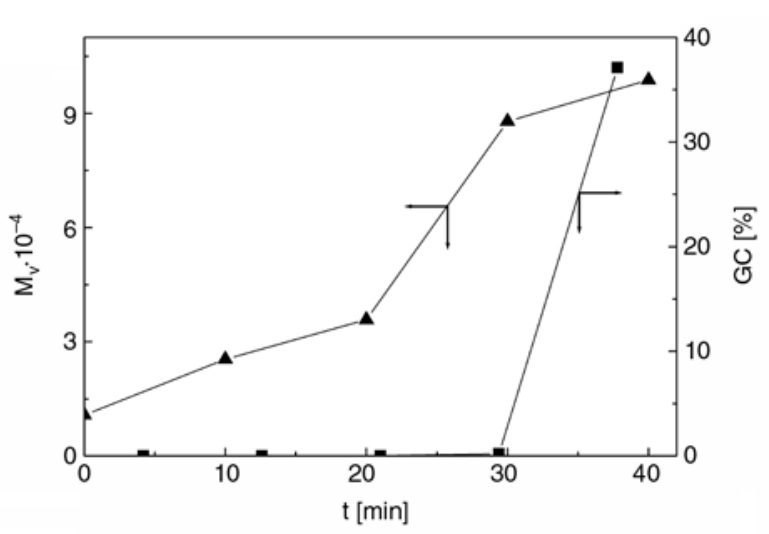

Figure 6. Effect of reaction time on chain extension reaction
DGEBA is also $1: 1$. The $\bar{M}_{V}$ of copolymer increases steadily with increasing reaction time. However, the gel content is almost zero during the beginning 30 minutes, and after that it increases rapidly with increasing reaction time. When the reaction time reaches $40 \mathrm{~min}$, the gel content of the copolymer is $37.1 \%$. The copolymer will be difficult to process when gel content is high. So, the best reaction time is $30 \mathrm{~min}$.

\subsection{Effect of the amount of DGEBA}

The effect of the amount of DGEBA on the $\overline{M_{V}}$ of PLLA/DGEBA copolymer is shown in Figure 7. The experimental conditions are shown in series $C$ of Table 1. No gel content is observed in this reaction system which can be explained by Figure 5 and Figure 6. The $\overline{M_{V}}$ of PLLA/DGEBA copolymer reaches 87900 , which is the highest, when the amount of DGEBA is $11.4 \mathrm{~g}$. On this point, the feed mole ratio of dicarboxylated PLLA to DGEBA is $1: 1$. At other points, the amount of carboxyl group and epoxy group is not equal, which causes inadequate reaction of dicarboxylated PLLA with DGEBA.

\section{Conclusions}

PLLA/DGEBA copolymers were successfully synthesized by chain extension of dicarboxylated PLLA with DGEBA-based epoxy resin. The viscosity average molecular weight of PLLA/DGEBA copolymer reached 87900 when reaction temperature, reaction time, and mol ratio of dicarboxylated PLLA to DGEBA is $150^{\circ} \mathrm{C}, 30 \mathrm{~min}$, and $1: 1$, respectively; while gel content of PLLA/DGEBA copolymer is almost zero.

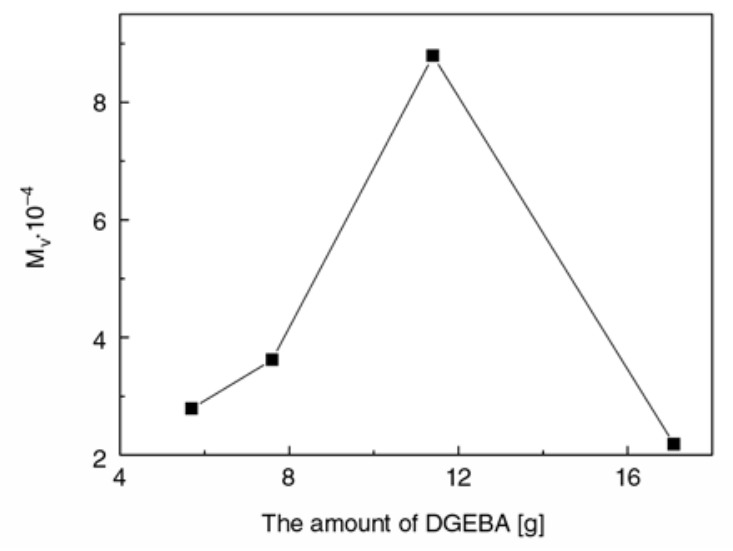

Figure 7. Effect of the amount of DGEBA on chain extension reaction 


\section{References}

[1] Teng C., Yang K., Ji P., Yu M.: Synthesis and characterization of poly(L-lactic acid)-poly( $\varepsilon$-caprolactone) multiblock copolymers by melt polycondensation. Journal of Polymer Science Part A: Polymer Chemistry, 42, 5045-5053 (2004).

[2] Kim H. S., Hwang M. O., Kim M. N., Yoon J. S.: Preparation of high-molecular-weight poly(L-lactic acid)-based polymers through direct condensation polymerization in bulk state. Journal of Applied Polymer Science, 100, 466-472 (2006).

[3] Moon S. I., Kimura Y.: Melt polycondensation of Llactic acid to poly(L-lactic acid) with $\mathrm{Sn}$ (II) catalysts combined with various metal alkoxides. Polymer International, 52, 299-303 (2003).

[4] Drumright R. E., Gruber P. R., Henton D. E.: Polylactic acid technology. Advanced Materials, 12, 18411846 (2000).

[5] Moon S. I., Lee C. W., Miyamoto M., Kimura Y.: Melt polycondensation of L-lactic acid with $\mathrm{Sn}$ (II) catalysts activated by various proton acids: a direct manufacturing route to high molecular weight poly $(\mathrm{L}-$ lactic acid). Journal of Polymer Science, Part A: Polymer Chemistry, 38, 1673-1679 (2000).

[6] Zhao Y. M., Wang Z. Y., Yang F.: Characterization of poly(D,L-lactic acid) synthesized by direct melt polymerization and its application in Chinese traditional medicine compound prescription microspheres. Journal of Applied Polymer Science, 97, 195-200 (2005).

[7] Stolt M., Viljanmaa M., Södergard A., Törmala P.: Blends of poly( $\varepsilon$-caprolactone-b-lactic acid) and poly(lactic acid) for hot-melt applications. Journal of Applied Polymer Science, 91, 196-204 (2004).

[8] Chen G. X., Kim H. K., Kim E. S., Yoon J. S.: Synthesis of high-molecular-weight poly(L-lactic acid) through the direct condensation polymerization of Llactic acid in bulk state. European Polymer Journal, 42, 468-472 (2006).
[9] Lee C. M., Kim E. S., Yoon J. S.: Reactive blending of poly(L-lactic acid) with poly(ethylene-co-vinyl alcohol). Journal of Applied Polymer Science, 98, 886890 (2005).

[10] Woo S. I., Kim B. O., Jun H. S., Chang H. N.: Polymerization of aqueous lactic acid to prepare high molecular weight poly(lactic acid) by chain-extending with hexamethylene diisocyanate. Polymer Bulletin, 35, 415-421 (1995).

[11] Kylma J., Seppala J. V.: Synthesis and charaterization of biodegradable thermoplastic poly(ester-urethane) elastomer. Macromolecules, 30, 2876-2882 (1997).

[12] Zhou Z. F., Xu W. B., Zuo C. R.: Method for preparing film poly(L-lactic acid) copolymer by inner plasticizing. China Patent, CN1243033, China (2005).

[13] Cohn D., Hotovely-Salomon A.: Biodegradable multiblock PEO/PLA thermoplastic elastomers: molecular design and properties. Polymer, 46, 2068-2075 (2005).

[14] Huh K. M., Bae Y. H.: Synthesis and characterization of poly(ethylene glycol)/poly(L-lactic acid) alternating multiblock copolymers. Polymer, 40, 6147-6155 (1999).

[15] Qian J. W., Wang M., Han D. L., Cheng R. S.: A novel method for estimating unperturbed dimension $[\eta]_{\theta}$ of polymer from the measurement of its $[\eta]$ in a nontheta solvent. European Polymer Journal, 37, 14031407 (2001).

[16] Kim K. W., Woo S. I.: Synthesis of high-molecularweight poly(L-lactic acid) by direct polycondensation. Macromolecular Chemistry and Physics, 203, 22452250 (2002).

[17] Hoppe C. E., Galante M. J., Oyanguren P. A., Williams R. J. J.: Epoxies modified by palmitic acid: From hot-melt adhesives to plasticized networks. Macromolecular Materials and Engineering, 290, 456-462 (2005). 